\title{
Application of Fuzzy Clustering Algorithm in Rotary Drill on Fault Diagnosis
}

\author{
Wei Hongbo, You Wen and Li Binglin \\ College of Electrical and Electronic Engineering,Changchun University of Technology,Changchun,130012,China \\ E-mail:15543143001@163.com
}

\begin{abstract}
As one of the key equipment of mining, rotary drills have a high incidence of failure. In the actual application, it is hard to fault diagnosis for roller transfer. In order to solve this problem, design a roller transfer control of fault self-diagnosis system with the fuzzy clustering analysis method combined with intelligent fault diagnosis technology, realizing the fault detection and prediction of rock drills, which can timely malfunctioning rotary drills. The fault information is given, determining the location, type and severity of the fault. For the improvement of rotary drills fault forecasting, judgment and processing have a vital role.
\end{abstract}

Keywords-Rotary drills; Intelligent fault diagnosis; Fuzzy clustering analysis method; Detection; Forecast

\section{INTRODUCTION}

Rotary drill is one of the key equipment in mining. Due to the increased levels of manufacturing and application, rotary drill automatic control technology gradually has high efficiency, intelligent development. The pressure of rotary drill is by turning the system to enhance the system and in the major components, the core is rotating motor rotation system. Due to the operator's field experience, ability is uneven, often resulting in motor burned. And because of the prevalence of vibration factors, cone bears wear, broken teeth, and so on. There is more objective of a rotary drill as a complex integrated systems and equipment in case of failure, maintenance personnel is difficult to detect and troubleshoot accordingly invest a lot of money every year I plant on the rotary motor shaft tooth repair, replacement, the system can effectively discover potential failure to locate the fault, guiding the operator promptly maintain equipment, reduce maintenance costs and improve the economic efficiency of enterprises.

\section{THE GENERAL IDEA}

Fuzzy fault detection and diagnosis technology is a diagnostic method way of thinking simulate the human brain using fuzzy theory to describe the fault condition and accurately determine the likelihood of failure. Essence of fuzzy fault diagnosis is by studying the correspondence between the state and characteristics of information between failures, draw the type of fault membership, thereby to automatically identify system status using cluster analysis of multivariate statistical analysis. The main idea of Intelligent Fault Diagnosis is through acquisition and processing system information, learn to use domain knowledge, judgment reasoning fault identification system status, to determine the cause of the failure to provide treatment program. Its purpose is that before the system fails, the system status monitoring and forecasting; when the system fails, the timely detection of the fault to determine, identify, locate, given fault information and provide treatment options. When rotary drill fault diagnosis clustering analysis based on different characteristics between samples, put a series of rotary drill some electrical signal in accordance with guidelines specified into different sub-categories, sub-categories to find each sample has some similarity to determine the properties of an object. The basic structure of the system is intelligent fault diagnosis technology as shown.

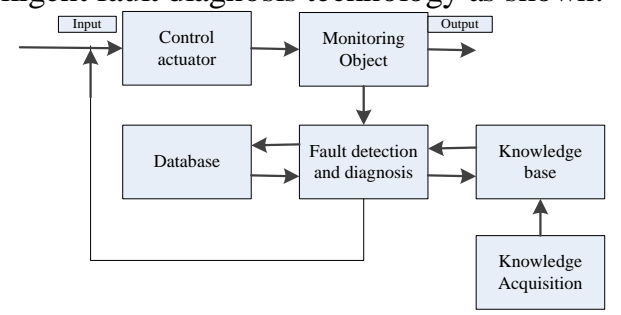

Figure 1. The basic structure of intelligent fault diagnosis technology

\section{MODEL ANALYSIS}

Rotation for the motor and rotary drill motor mathematical model enhance the established motor vector control model, the model is as follows:

$$
\left[\begin{array}{l}
u_{s \alpha} \\
u_{s \beta} \\
u_{r \alpha} \\
u_{r \beta}
\end{array}\right]=\left[\begin{array}{cccc}
R_{1}+L_{s} P & 0 & L_{m} P & 0 \\
0 & R_{1}+L_{s} P & 0 & L_{m} P \\
L_{m} P & \omega_{r} L_{m} & R_{2}+L_{s} P & \omega_{r} L_{r} \\
-\omega_{r} L_{m} & L_{m} P 0 & -\omega_{r} L_{r} & R_{2}+L_{r} P
\end{array}\right]\left[\begin{array}{l}
i_{s \alpha} \\
i_{s \beta} \\
i_{r \alpha} \\
i_{r \beta}
\end{array}\right]
$$

Above model includes a three-phase induction motor inductance term, mutual terms with the stator and rotor winding resistance term, this model is as the basis, through mathematical modeling and theoretical analysis, external installation of precision voltage and current sensor and the actual motor resistance, inductance, mutual inductance and other parameters, simultaneous sampling of voltage, current and phase angle and other operating parameters and theoretical analysis are into the above model.

Through the installation of the drive and the external current sensors, voltage, motor acquisition and hardware to each sample value sampling communicate via PLC, the PLC data capture database records storage process, according to the inverter internal fault threshold is set to determine whether there is a failure.

Finally, turning to enhance the status of the motor in the PC - Siemens touch screen interactive interface 
development, suggesting that some workers in the field of fault diagnosis and troubleshooting tips.

\section{ROTARY DRILL FAULT DIAGNOSIS}

After the completion of the electronic signal acquisition, data storage, the need for a common rotary drill rotary motor failure analysis, the analysis is a theory, systematic, multi-factor, strong coupling characteristics. In response to these characteristics, according to the rotary drill existing technical indicators and overall performance rating method based on fuzzy clustering objective function of fuzzy clustering, which is calculated as a result of having a simple, is easy to implement and so on. Specific uses fuzzy C-means clustering algorithm combined with fuzzy transitive closure for self-diagnosis of faults.

Failure to identify the characteristics of the process include the following two aspects

(1) Extract effective characteristic signal, extract the effective sign of the signal from the state for diagnostic characteristic signal, the analysis of the rotary drill signs signal pattern recognition

(2) According to the model identified the state for rotary drill prediction and diagnosis, prediction and diagnosis of the final results according to the state to control the system and decision-making. Identification process fault characteristics are shown in Fig.2.

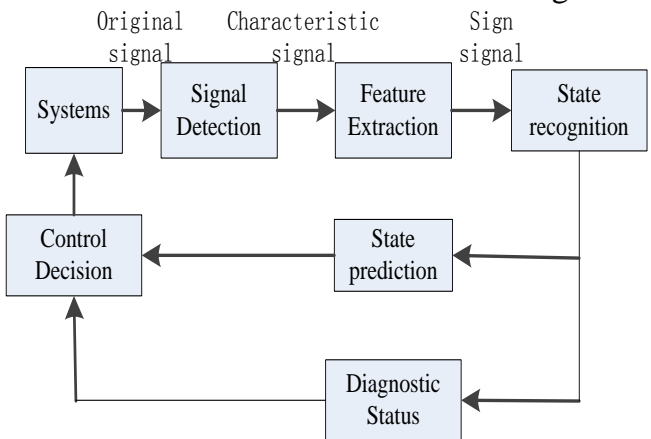

Figure 2. fault characteristics identification process diagram

Combined with field acquisition parameters and intelligent control algorithms, the system can now accurately diagnose the fault information listed in the following table 
TABLE I. THE FAULT INFORMATION TABLE

\begin{tabular}{|c|c|c|c|}
\hline $\begin{array}{l}\text { Malfunct } \\
\text { ion }\end{array}$ & Contents & The reason & Countermeasure \\
\hline 1 & Overcurrent & $\begin{array}{l}\text { Output short-circuit occurs, grounding (by } \\
\text { motor burned, insulation deterioration, } \\
\text { damage caused by contact with the cable, } \\
\text { grounding, etc.). }\end{array}$ & $\begin{array}{l}\text { Cause investigation, reset after the } \\
\text { implementation of countermeasures }\end{array}$ \\
\hline 2 & Earthing & $\begin{array}{l}\text { Ground (by burning, insulation deterioration, } \\
\text { cable breakage caused by contact with the } \\
\text { motor, the ground, etc.) occurred in the } \\
\text { inverter output side }\end{array}$ & $\begin{array}{l}\text { Cause investigation, reset after the } \\
\text { implementation of countermeasures }\end{array}$ \\
\hline 3 & Fuse & $\begin{array}{l}\text { Due to short-circuit the inverter output } \\
\text { side grounded. Output transistor is damaged } \\
\text { goods. Confirm whether a short circuit } \\
\text { between the following terminals. If a short } \\
\text { circuit is the output transistor being } \\
\text { damaged. }\end{array}$ & $\begin{array}{l}\text { Cause investigation, after the } \\
\text { implementation of countermeasures, } \\
\text { replace the drive }\end{array}$ \\
\hline & $\begin{array}{l}\text { The main circuit } \\
\text { voltage is too }\end{array}$ & $\begin{array}{l}\text { Deceleration time is too short, the } \\
\text { energy generated from the motor too }\end{array}$ & $\begin{array}{l}\text { Increase the deceleration time or } \\
\text { connecting the braking resistor } \\
\text { (Braking Resistor Unit) }\end{array}$ \\
\hline 4 & large & Power supply voltage is too high & $\begin{array}{l}\text { Decrease in the supply voltage } \\
\text { specifications }\end{array}$ \\
\hline 5 & $\begin{array}{l}\text { Main circuit } \\
\text { undervoltage }\end{array}$ & $\begin{array}{l}\text { 1, the input power supply has missing items } \\
2 \text {, the occurrence of an instantaneous power } \\
\text { failure } \\
3 \text {, the input power terminals loose } \\
\text { 4, the voltage variation of the input power is } \\
\text { too }\end{array}$ & $\begin{array}{l}\text { Cause investigation, reset after the } \\
\text { implementation of countermeasures }\end{array}$ \\
\hline 6 & $\begin{array}{l}\text { The main } \\
\text { circuit voltage } \\
\text { failure }\end{array}$ & $\begin{array}{c}\text { 1, the power supply has missing items } \\
\text { 2, the occurrence of an instantaneous power } \\
\text { failure } \\
3 \text {, the input power terminals loose } \\
\text { 4, the voltage variation of the input power is } \\
\text { too } \\
\text { 5, the phase voltage is not good balance }\end{array}$ & $\begin{array}{l}\text { Cause investigation, reset after the } \\
\text { implementation of countermeasures }\end{array}$ \\
\hline \multirow{3}{*}{7} & \multirow{3}{*}{$\begin{array}{l}\text { Motor } \\
\text { overheating } \\
\text { fault }\end{array}$} & \multirow{3}{*}{ Motor overheating } & $\begin{array}{l}\text { Resize the load, acceleration and } \\
\text { deceleration time, period }\end{array}$ \\
\hline & & & $\begin{array}{c}\text { Correction voltage frequency } \\
\text { characteristic }\end{array}$ \\
\hline & & & Check the motor rated current setting \\
\hline \multirow{3}{*}{8} & \multirow{3}{*}{ Motor overload } & $\begin{array}{c}\text { 1.the load is too large, the acceleration and } \\
\text { deceleration time period is too short }\end{array}$ & $\begin{array}{c}\text { Resize the load, acceleration and } \\
\text { deceleration time period }\end{array}$ \\
\hline & & $\begin{array}{l}\text { 2.the frequency characteristic of the high } \\
\text { voltage voltage }\end{array}$ & $\begin{array}{c}\text { Adjust the voltage and frequency } \\
\text { characteristics }\end{array}$ \\
\hline & & 3. Set the rated motor circuit properly. & $\begin{array}{l}\text { Confirm the set value of motor rated } \\
\text { current }\end{array}$ \\
\hline \multirow{3}{*}{9} & \multirow{3}{*}{$\begin{array}{l}\text { Inverter } \\
\text { overload }\end{array}$} & $\begin{array}{c}\text { 1.the load is too large, the acceleration and } \\
\text { deceleration time period is too short }\end{array}$ & $\begin{array}{c}\text { Resize the load, acceleration and } \\
\text { deceleration time, period }\end{array}$ \\
\hline & & $\begin{array}{l}\text { 2.the frequency characteristic of the high } \\
\text { voltage voltage }\end{array}$ & $\begin{array}{l}\text { Adjust the voltage and frequency } \\
\text { characteristics }\end{array}$ \\
\hline & & 3.a small inverter capacity & Replace high-capacity drive \\
\hline \multicolumn{4}{|c|}{$\begin{array}{ll}\text { Above is the use of the motor and inverter common } & \text { approach to } n \\
\text { alt intelligent fault diagnosis technology field } & \text { intelligent faul } \\
\text { agnostics, fault is divided into nine kinds, the system } & \text { motor is runn } \\
\text { ts each of the causes and failure to produce relevant } & \text { overcurrent wa }\end{array}$} \\
\hline
\end{tabular}


indicates the reason for failure may occur, such as the inverter output short circuit, grounding (by motor burned insulation deterioration side, cable breakage caused by contact with the ground, etc.) and other information, and then gives the corresponding countermeasures in countermeasures bar. Visualization and human-computer interaction capability of the system is greatly improved, which can better guide the site operator to identify the exact point of failure in a timely manner and troubleshooting.

\section{CONCLUSIONS}

The use of fuzzy clustering analysis method can detect rotary drill failure, failure to give information and to determine the fault location, type and severity; running state prediction equipment, life and faults. It can fail rate from the current $4.5 \%$ to $3 \%$, which is $30 \%$ reduction rate, utilization by the current $60 \%$ to $70 \%$. For different parts of the fault, the type and extent of control and given the appropriate treatment options, and technology.

\section{REFERENCES}

[1] Hubei strengthen Intelligent Fault Diagnosis of Changsha: Hunan University Press, 2006.
[2] Xu Min, Zhao Yideng equipment troubleshooting manual Xi'an: Xi'an Jiaotong University Press, 2008.

[3] Yu and Ji, HAN Qing large, Li Shen equipment troubleshooting Engineering Beijing: Metallurgical Industry Press, 2011.

[4] Jian Jun, tin, gold soft shock new method of analog circuit fault diagnosis - fuzzy clustering diagnostics Beijing University of Posts and Telecommunications Technology, 2009,12 (3): 77-81.

[5] Zhong Ru Tang fuzzy set theory constructed diesel engine fault diagnosis expert system Dalian Maritime University,2010,16 (4): 375-380.

[6] $\mathrm{Mi}$ is built of stone to Germany fuzzy ISODATA clustering method and its application in fault diagnosis of Tongji University, 2010,25 (1): 66-70.

[7] handsome Renjun, Wu Huiying, Li Wei fuzzy clustering analysis in turbogenerator rotor vibration faults in the application of Electrical Engineering, 2012,17 (1): 20-37.

[8] Chen Kai, Zhu Jie, Wang Hao-line fuzzy clustering method of complex system fault diagnosis [J] Shanghai Jiaotong University, 2013,32 (6): 61-64 .

[9] Lu Qing, Feng Jinfu, Xu et Nie light half a fault diagnosis method based on fuzzy clustering Test and Measurement Technology, 2011,21 (6): 551-556.

[10] Change Jiangshe, Leung Y Improved possibilistic c-means clustering algorithms, IEEE Trans Fuzzy system, 2012, 12 (2): 209 $\sim 217$. 